\title{
LARGE SCALE PRODUCTION OF 805-MHZ PULSED KLYSTRONS FOR THE SPALLATION NEUTRON SOURCE PROJECT*
}

\author{
S. Lenci, E. Eisen, CPI, Palo Alto, CA, USA
}

\section{Abstract}

The Spallation Neutron Source (SNS) is an acceleratorbased neutron source being built in Oak Ridge, Tennessee, by the U.S. Department of Energy. CPI is supporting the effort by providing 81 pulsed klystrons for the superconducting portion of the accelerator. The primary output power requirements are $550 \mathrm{~kW}$ peak, $49.5 \mathrm{~kW}$ average at $805 \mathrm{MHz}$, with an electron beam-to-rf conversion efficiency of $65 \%$ and an $\mathrm{rf}$ gain of $50 \mathrm{~dB}$. Tests were performed that verified the tube could provide over $1 \mathrm{MW}$ peak with minimal changes. Through April 2005, 77 units have been factory-tested. Performance specifications, computer model predictions, operating results, and production statistics will be presented.

\section{INTRODUCTION}

CPI, formerly of the Electron Device Group of Varian Associates, has a long history of building high-power pulsed UHF klystrons for many applications. This $550 \mathrm{~kW}$ pulsed klystron will be used in the Superconducting linac of SNS, where up to 12 klystrons will be powered from a single power supply. Since the klystrons do not have a modulating anode, the cathode voltage will determine the beam current. The system must accommodate variation in klystron perveance as well as end of life operation. The result is the klystron with the highest cathode voltage requirement will determine the operating level of the entire group.

Although the peak and average rf power requirements are fairly modest, the combination of high efficiency $(65 \%)$ and high gain $(50 \mathrm{~dB})$ provided quite a challenge. The constraint on beam operation and microperveance limited design options.

Originally 65 of the $550-\mathrm{kW}$ tube, designated VKP$8291 \mathrm{~A}$, were ordered. The exercise of options increased the total to 81 units. Through April 2005, a total of 77 units have been factory tested and shipped, 70 of which have been installed and 53 commissioned.

\section{DESIGN}

The efficiency requirement of $65 \%$ was the key concern in the rf design. To achieve this, a six-cavity rf-circuit, including one tuned slightly below the second harmonic of the operating frequency, was chosen. The design is optimized to provide the required efficiency and gain without compromising bandwidth. The first two cavities are staggered around the operating frequency to provide the bandwidth. Next is the second-harmonic cavity followed by two inductively tuned cavities to optimize the electron bunching. The output cavity then extracts energy from the beam.

The electron gun is a low-perveance, diode design. The voltage gradients of the gun electrodes are less than 60 $\mathrm{kV} / \mathrm{cm}$, which will ensure long life for this long pulse device. The peak cathode loading is $.6 \mathrm{Amps} / \mathrm{cm}^{2}$, which yields a predicted cathode life in excess of 100,000 hours.

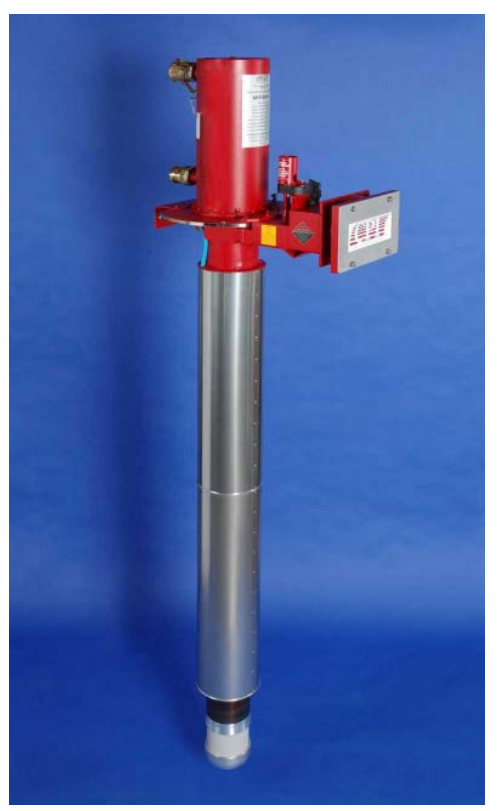

Figure 1: VKP-8291A Klystron

The klystron is required to operate vertically with the gun down and is shown Figure 1. Its overall length is 105 inches $(267 \mathrm{~cm})$.

The rf energy is extracted through a single window with an alumina ceramic. The pillbox window is designed around WR-975 waveguide. A bolt-on waveguide elbow also transitions the guide to WR-1150.

The collector is designed to dissipate the entire beam energy. It is made from a thick-walled copper cylinder with grooves milled into the outer wall for the coolant to pass. The water-jacket is part of the brazed collector assembly. The proof test pressure is 200 psi (13.6 bar).

\section{TEST RESULTS}

The klystron performance through the production run has been very consistent. Table 1 compares the typical performance to the specification.

*Work supported by US Department of Energy 
Table 1: VKP-8291A Performance Summary

\begin{tabular}{|l|c|c|}
\hline & $\begin{array}{c}\text { VKP-8291A } \\
\text { Specification }\end{array}$ & $\begin{array}{c}\text { VKP-8291A } \\
\text { Typical }\end{array}$ \\
\hline Frequency & $805 \mathrm{MHz}$ & $805 \mathrm{MHz}$ \\
\hline Peak Cathode Voltage & $75 \pm 1.5 \mathrm{kV}$ & $75 \mathrm{kV}$ \\
\hline Peak Beam Current & $11.5 \mathrm{Amps} \mathrm{max}$ & $11.2 \mathrm{Amps}$ \\
\hline Perveance & $.55 \mathrm{nom}$ & .54 \\
\hline Peak Output Power & $550 \mathrm{~kW} \mathrm{~min}$ & $560 \mathrm{~kW}$ \\
\hline-1 dB Bandwidth & $\pm 1.3 \mathrm{MHz} \mathrm{min}$ & $\pm 2 \mathrm{MHz}$ \\
\hline Efficiency & $65 \% \mathrm{~min}$ & $67 \%$ \\
\hline RF Duty Cycle & $9 \%$ & $9 \%$ \\
\hline RF Pulse Length & $1.5 \mathrm{msec}$ & $1.5 \mathrm{msec}$ \\
\hline Peak RF Drive Power & $5.5 \mathrm{Watts}$ & $4.3 \mathrm{Watts}$ \\
\hline Gain & $50 \mathrm{~dB}$ min & $51 \mathrm{~dB}$ \\
\hline
\end{tabular}

The transfer and bandpass curves of 25 units, along with the simulation predictions, have been plotted together for comparison as seen in Figures 2 and 3. The prototype klystron stands out as the only unit that did not meet the efficiency requirement. Otherwise the variation among the units is quite reasonable. Additionally each klystron has to demonstrate stable performance and achieve $80 \%$ of its rated power at six equally spaced positions of a 1.2:1 mismatch.

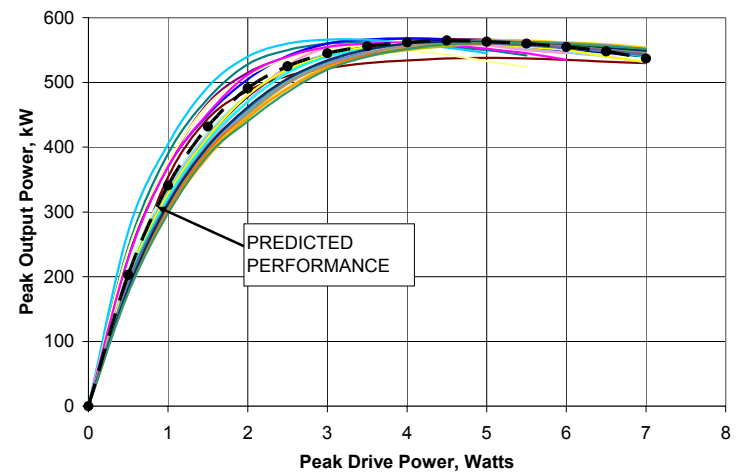

Figure 2: VKP-8291A Transfer Curves

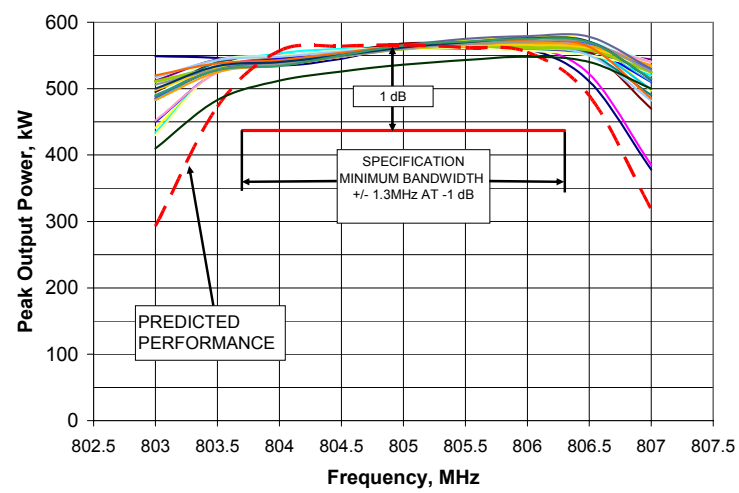

Figure 3: VKP-8291A Bandpass Curves
The Phase Transfer Characteristic (the insertion phase of the klystron) is required to be a smoothly varying, monotonic function as the drive power is increased from $20 \%$ to $100 \%$ of the saturated drive, and is measured on each unit. The phase shift was measured in $0.5 \mathrm{~dB}$ increments as the drive power was reduced from saturated output $(0 \mathrm{~dB})$ to $-13.5 \mathrm{~dB}$ ( $4.5 \%$ of saturated drive), see Figure 4.

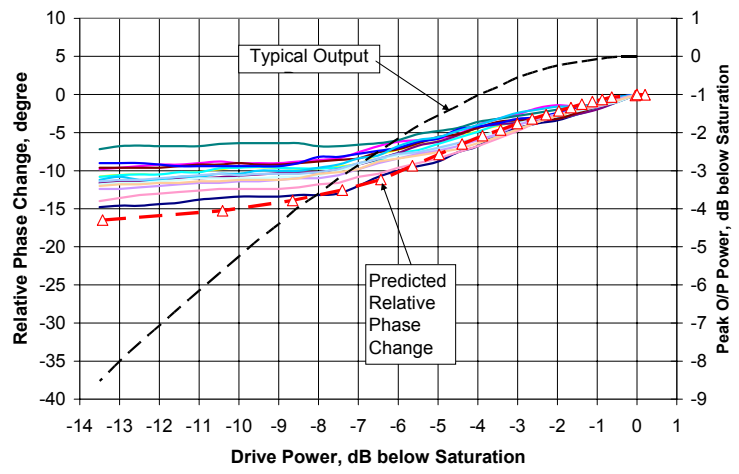

Figure 4: Relative Phase Change vs. Drive Power

\section{MW CAPABILITY}

SNS originally targeted the High Energy Beam Transfer (HEBT) portion of the accelerator to use $5 \mathrm{MW}$ klystrons. SNS is now expecting to need as little as $1 \mathrm{MW}$ of $\mathrm{rf}$ power. The VKP-8291A had been tested to $800 \mathrm{~kW}$ peak previously without difficulty. Before going to 1 MW, an analysis of the $\mathrm{rf}$ circuit was performed. The coupling of the output cavity needed to be adjusted for the lower beam impedance to improve performance. Analysis of the gun at the higher voltage showed the gradients to be acceptable.

A production unit was chosen for the testing. Testing was performed at the standard $1.5 \mathrm{msec}$ pulse length, but the average power was limited to $50 \mathrm{~kW}(\mathrm{PRF}=30 \mathrm{~Hz})$ to stay within the limits of the body cooling and output load. The output cavity coupling adjusted externally. The klystron was operated up to $1.3 \mathrm{MW}$ of peak power without difficulty. The output power and efficiency versus beam voltage are presented in Figure 5.

The tests showed the VKP-8291A rf circuit is capable of $1 \mathrm{MW}$ peak power operation. To achieve this at the nominal $9 \%$ duty will require improved cooling of the rf circuit. Additional action items include optimizing the output cavity coupling and cavity tuning. The gun gradients need to be reviewed to ensure reliable operation at the higher beam voltage. A $1 \mathrm{MW}$ version would have the same mechanical interface as the $550 \mathrm{~kW}$ tube and fit into the same electromagnet. This commonality would allow the klystron to be easily assimilated into the SNS gallery. 


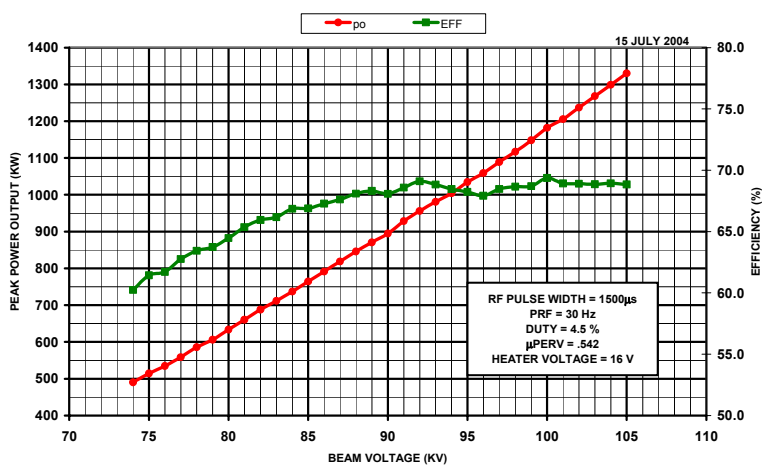

Figure 5: High Peak Power Operation

\section{PRODUCTION RESULTS}

The production rate to support this contract has provided an opportunity to evaluate operational and performance variation. Some of the variation is due to manufacturing tolerances, such as spacing in the gun that directly influence the microperveance, and some are due to optimizing performance at test. The gain and bandwidth are greatly influenced by the cavity tuning. We found if the gain is too high, the tube is much closer to instabilities should the magnet settings or beam voltage drift. Our goal is to set the gain just below $51 \mathrm{~dB}$ to provide margin. Figure 6 displays the key performance data through the 77 units tested to date.

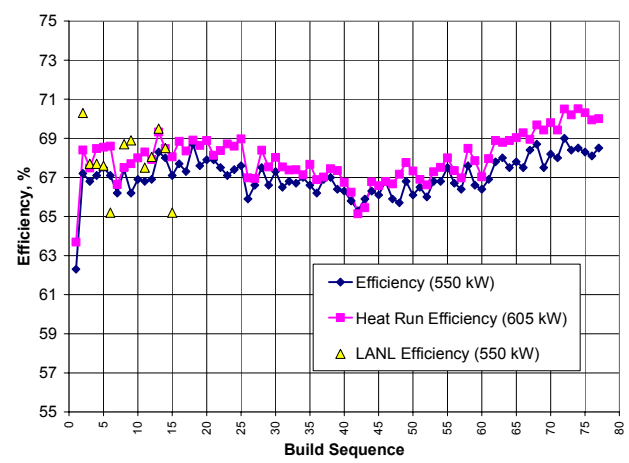

Figure 6: Summary of Performance in Build Sequence

At the time the $30^{\text {th }}$ unit was being shipped, LANL approached CPI regarding delivery of additional units within contract period. A Critical Path Analysis was performed to analyze the production capability. Each process from our supplier's capabilities through packaging and shipment was evaluated. Equipment and personnel limitations were reviewed.

Fortunately equipment resources, especially the test stand, were available and we determined 4 units/month was achievable with a modest investment in fixtures. Based on this analysis and delivery commitment, CPI was awarded additional units. The actual delivery by month along with the original schedule for 65 units is presented in Figure 7. The remaining 4 units are to be spares. ORNL has graciously allowed their delivery to move out to allow the test stand to be used for other product.

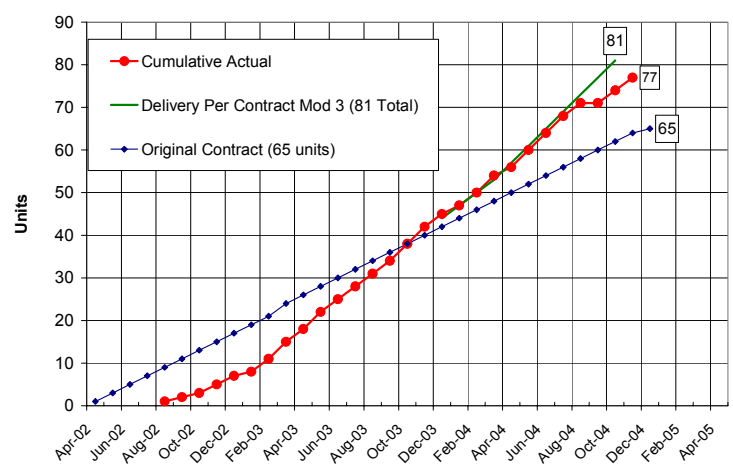

Figure 7: Delivery Schedule

\section{CONCLUSION}

The measured results instill high confidence in our simulation codes to design products with minimal cold testing. After the prototype, all aspects of the specification have been met on all tubes. The tube also demonstrated a high degree of stability under various operating conditions. The design has enough margin to allow a 1 MW version at $9 \%$ duty by making minimal changes, as seen in measured test data.

\section{ACKNOWLEDGEMENT}

The authors would like to thank their co-workers at CPI for their contributions throughout the development and production of this product. We would also like to thank the CPI management team for their support. Finally many thanks go to the technical contacts at the supporting labs, in particular Dan Rees and Paul Tallerico at Los Alamos National Lab, and Mike McCarthy at Oak Ridge National Lab.

\section{REFERENCES}

[1] http://www.sns.org.

[2] S. Lenci and E. Eisen, "Development and Production of An 805-MHz, $550 \mathrm{~kW}$ Pulsed Klystron For The Spallation Neutron Source," $6^{\text {th }}$ Workshop on High Energy Density and High Power RF, AIP Proceedings, Volume 691(2003), pp 312-322.

[3] S. Lenci, E. Eisen, B Stockwell, "Development of An $805-\mathrm{MHz}, 550 \mathrm{~kW}$ Pulsed Klystron For The Spallation Neutron Source," PAC'03, May 2003, p. 1122.

[4] S. Lenci, E. Eisen,, "Large Scale Production of An 805-MHz, $550 \mathrm{~kW}$ Pulsed Klystron For The Spallation Neutron Source,” EPAC’04, July 2004, p. 1114. 